\title{
Improvement of chilled seabass sperm conservation using a cell culture medium
}

\author{
C. Fauvel ${ }^{1, *}$, S. Boryshpolets ${ }^{2}$, J. Cosson ${ }^{2}$, J. G. Wilson Leedy ${ }^{3}$, C. Labbé ${ }^{4}$, P. Haffray ${ }^{5}$, M. Suquet ${ }^{6}$
}

\author{
1 Ifremer, UMR 5119 ECOSYM, UM2 - UM1 - CNRS - IRD - IFREMER, Station Expérimentale d'Aquaculture, \\ 34250, Palavas, France \\ ${ }^{2}$ Faculty of Fisheries and Protection of Waters, University of South Bohemia in Ceske Budejovice, South \\ Bohemian Research Center of Aquaculture and Biodiversity of Hydrocenoses, Vodnany, Czech Republic \\ ${ }^{3}$ Department of Biological Sciences, University of Idaho, Center for reproductive biology, Moscow, ID, USA \\ ${ }^{4}$ INRA, UR 1037 Scribe, Rennes, France \\ ${ }^{5}$ SYSAAF, Scribe, Rennes, France \\ ${ }^{6}$ Ifremer, UMR 100, Station Expérimentale d'Argenton, Argenton, France \\ *: Corresponding author : Christian Fauvel, email address : Christian.Fauvel@ifremer.fr
}

\begin{abstract}
:
The sperm of seabass is very fragile and it quickly loses its ability to fertilize after collection either if kept undiluted or in classic saline media. In order to avoid cryopreservation when only short conservation is required, the process of sperm management including sperm collection, sperm dilution rate in storage medium and storage medium composition, was subject to experimental trials. A concentration of $20 \%$ urine generated a low $\mathrm{pH}$ of seminal fluid, and it immediately altered the motility ability. However, $\mathrm{pH}$ did not seem to be the key agent of motility prevention since sperm dilution in Leibovitz culture medium (L15) or in classic saline medium both presenting a similar low pH (7.3) did not affect motility. L15 increased the duration of sperm survival by 2 days at $4^{\circ} \mathrm{C}$ after collection. Moreover, dilution could be restricted to $1: 3(\mathrm{v}: \mathrm{v})$ for conservation of chilled sperm. Chilled sperm could be cryopreserved with no more damages than those observed after freezing of fresh sperm.
\end{abstract}




\section{Introduction}

European seabass (Dicentrarchus labrax) fry industrial production has been based on spontaneous spawning of captive broodstocks. But in the last decade the need for controlled multiple crosses in genetic purposes such as the study of genotypeenvironment interactions (Dupont-Nivet et al., 2010), has required male and female gamete management studies and the implementation of optimized, then standardized, fertilization conditions (Fauvel et al.,1999; Fornies et al.,2001).

Cryopreservation protocols for seabass sperm were successfully implemented using two kind of saline media characterized by a) high osmolarity, low $\mathrm{pH}$ and fetal bovine serum, $\mathrm{pH}$ being the motility inhibiting factor (Villani \& Catena 1991, Sansone et al., 2002) or b) low osmolarity, high $\mathrm{pH}$ and bovine serum albumin or BSA in which motility is controlled by osmolarity (Fauvel et al., 1999). These media were supplemented with cryoprotectants such as dimethyl sulfoxyde (DMSO), ethylene glycol or glycerol (Fauvel et al.,1998 Sansone et al., 2002 , Peñaranda et al., 2008) that increased by themselves the osmotic pressure hence inducing uncontrolled partial motility in the samples. Moreover, Peñaranda et al. (2008) demonstrated a significant protecting effect of BSA when it was added at $1-2 \%$ to the conservation media. However, in field operations including seabass sampling, handling of large number of samples and transportation before freezing, the success of cryopreservation had been unreliable (unpublished) and had to be improved.

The ability of fish sperm to fertilize eggs can be maintained for different intervals of time after collection if the conditions of conservation are adapted. For long term conservation, cryopreservation is the best solution provided the sperm is still alive at freezing. In that case, the basic dilution medium is designed to prevent any motility of sperm in order to limit energy consumption to basic metabolism. Then specific cryoprotectants are added. For example, the dilution of Lateolabrax

60 maculeatus sperm in a simple $\mathrm{NaCl}$ solution with either 5 or $10 \%$ dimethyl 61 sulfoxyde (DMSO) was sufficient to protect it at freezing (Gwo, 2010). 
For short term use or before cryopreservation, the sperm of fish can be chilled for various storage durations according to species, dilution media, dilution rate and storage temperature (Bobe \& Labbé, 2009). For these authors, the major requirements for chilled conservation are a temperature between 0 and $4^{\circ} \mathrm{C}$, the presence of an antibiotic cocktail to prevent any bacterial development, and, when necessary, a dilution in a medium mimicking seminal plasma composition. The addition of membrane protectants generally used for cryopreservation such as amino acids, proteins, antioxidants and sugars was not documented enough to be recommended in the design of chilled storage medium .

The quality of fish sperm should be best assessed by its fertilizing ability. However, due to the multifactorial determinism of fertilization success including the highly variable quality of eggs (Bobe \& Labbé, 2010), fertilization environment (Fauvel et al., 1993), sperm to egg ratio and sperm intrinsic quality (Cabrita et al., 2009), other parameters such as motility (Kime et al., 2001, Rurangwa et al., 2004) may be more relevant to analyze quickly the variations of sperm quality in relation to different factors.

As a general feature, fish sperm is not motile in the genital tract, the motility of sperm is triggered by the change of sperm environment at ejaculation (Alavi and Cosson, 2006) or later, when subjected to ovum environment in the case of herring (Clupea pallasi) (Cherr et al., 2008). The motility usually concerns all spermatozoa concomitantly but in laboratory conditions, a double dilution procedure is recommended (Billard and Cosson, 1992). The activation and the duration of motility are strongly linked to energy content of the cells (Christen et al., 1987; Boryshpolets et al., 2009; Dreanno et al., 1999) and to the capacity of the membrane to allow ionic transfers which trigger the enzymatic cascade responsible for motility (Inaba, 2008). For marine fish, sperm motility is triggered by the abrupt increase of osmolarity due to its release into seawater at ejaculation while in freshwater fish, either osmolality or ionic composition triggers (Morisawa et al., 1983), and regulate sperm activity 
(Wilson-Leedy et al., 2009). Potassium drop triggers motility in salmonids and sturgeons (Alavi and Cosson, 2006) moreover in sturgeons, $\mathrm{K}^{+}$may also have a protecting effect of sperm during short term storage. (Tsvetkova et al., 1996). A possible role of potassium ion in marine fish sperm motility control has not been documented so far. Finally, Morisawa and Morisawa (1988) proposed a maturational effect of bicarbonate on trout and chum salmon sperm in the genital tract, improving motility at activation. In marine fish, the basic non activating media or NAM, are generally isotonic to seminal fluid and their compositions can mimic the ionic content of seminal plasma (Suquet et al., 1993; Asturiano et al., 2004) or they can be especially designed to improve the fertililizing ability of spermatozoa

102 (Villani \& Catena, 1991; Sansone et al., 2001; Tanaka et al., 2002).

The success of cryopreservation of marine fish sperm has been very variable and highly dependent on the intrinsic quality of sperm and extrinsic factors such as the presence of urine in semen at collection (Dreanno et al., 1998) and the interval of time between sperm collection/dilution and cryopreservation (Sansone et al., 2001). The chilled storage capacity of seabass sperm is limited to 6 hours according to Sansone 2001. The dilutions ranging from 1:6 to $1: 20(\mathrm{v}: \mathrm{v})$ of sperm in mineral non activating media increased the time interval by which the motility potential had been sustained with reduced damage at $0-2$ to $4^{\circ} \mathrm{C}$ (Peñaranda et al.,

111 2008).

112 In order to improve the process including sperm collection, transport and cryopreservation in seabass aquaculture management, the present work aims at

114 assessing the effect of urine of sperm motility and at comparing the capacities of mineral storage diluents and cell culture media to maintain the quality of sperm

116 during chilled storage based on sperm motility, sperm cryopreservation ability and 117 fertilization ability.

\section{General protocol}


121 The sperm used in the current experiments were collected from $400 \mathrm{~g}$ mean weight

122 individuals of a broodstock subject to natural variations of photoperiod and

123 temperature. Experiments took place in January which corresponds to the natural

124 reproductive season of wild stock in the gulf of Lion (NW Mediterranean). Mature

125 males were randomly selected and their sperm was collected. After stripping, the

126 breeders were then transferred to other facilities in order to avoid consecutive

127 semen collection from a same individual. The males were fished without

128 anesthetics and immediately wrapped in a dark wet towel to limit stress and fish

129 movement during sperm collection. A volume of $2 \mathrm{ml}$ semen was sipped with $5 \mathrm{ml}$

130 syringes at the gonopore after gentle pressure of the male abdomen. Collection

131 was immediately stopped when variation of sperm aspect occurred in order to

132 avoid any visible contamination with urine. In order to obtain perfectly

133 uncontaminated sperm, the testes of 2 males were dissected and opened and

134 sperm was directly sipped in situ. The syringes were stored into a styrofoam box,

135 upon a bed of crushed ice for a maximum of 20 minutes. Neither post collection

136 wounds nor mortality were observed on sampled fish.

137 The osmolality of seminal fluid was assessed on triplicate $100 \mu \mathrm{l}$ samples by 138 means of a microosmometer (Roebling) which detects freezing point depression.

139 Seminal liquid was prepared by sperm centrifugation at $6000 \mathrm{rpm}(5600 \mathrm{~g})$ for 15

140 minutes. Semen $\mathrm{pH}$ was measured in triplicates using an IFSET multiparameter

141 analyser (IQ Scientific Instruments) in a drop (10 $\mu \mathrm{l})$ of sample.

142 In order to assess sperm motility features, samples were subjected to a two step

143 dilution procedure according to Fauvel et al. (2009), driving to 1:2000 final dilution.

144 The motilities of activated sperms were immediately recorded through a dark field

145 equipped video microscope (Axiolab, Zeiss + SSC-D50AP videocamera, Sony) at

146 X20 magnification The process allowed secure assessment of motility at 10

147 seconds after activation.

148 The movies were processed using Virtualdub (www.virtualdub.org) free software

149 and analyzed through ImageJ CASA plugin according to Wilson-Leedy \& Ingerman

150 (2007). The motility of spermatozoa was quantified by the percentage of motile 
cells at $10 \mathrm{~s}$ (initial motility) and the average path velocity (VAP) calculated from $1 \mathrm{~s}$ trajectory data at $10 \mathrm{~s}$ intervals until any movement ceased.

\section{Urine contamination trials.}

In order to avoid contamination by sperm, urine was collected from juvenile females of $600 \mathrm{~g}$ that never underwent vitellogenesis hence preventing possible estradiol effect. Then urine was kept on ice until use. Urine was added to sperm at $0 \%, 10 \%$ and $20 \%$ vol. $\mathrm{pH}$, osmolality of modified seminal liquid and initial motility of spermatozoa at activation were assessed.

\section{Sperm storage}

Sperm aliquots were stored at $4^{\circ} \mathrm{C}$ either undiluted or diluted at different ratios in non activating medium or NAM (osmolality 213 mosm, $\mathrm{pH} 7.7$ ) described by Fauvel et al. (1998) as a reference, and in Leibovitz L15 cell culture medium modified according to the aims of the experiments. All the media were added $1 \mathrm{mg}$ $\mathrm{ml}^{-1}$ gentamycine sulfate (Sigma) prior to use. In order to prevent sperm initial motility, the osmolality of Leibovitz L15 (Sigma) was decreased to 213 mOsm by dilution in distilled water in a ratio 63:37 (v:v).

\section{Medium improvement trials.}

In order to evaluate the effect of the $\mathrm{pH}$ of storage medium on sperm quality, the $\mathrm{pH}$ of Leibovitz medium (originally 7.34 ) called L7 was brought to 8.10 called L8 by addition of $\mathrm{NaOH}(1 \mathrm{M})$. The effect of the addition of potassium to the conservation medium was tested after addition of potassium bicarbonate $\left(\mathrm{KHCO}_{3}, 20 \mathrm{mM}\right)$ to $\mathrm{L} 15$ media and pH was adjusted to either 7.34 (LK7) or 8.10 (LK8). In order to evaluate the possible effect of the dilution rate on sperm survival and then to optimize it for semen storage experiments, semen samples were diluted to 1:2, 1:3 and 1:5 (v:v) and they were stored in either $100 \mu \mathrm{l}$ or $1.5 \mathrm{ml}$ aliquots. 
in order to assess sperm quality as a function of storage conditions, samples were held at $4^{\circ} \mathrm{C}$ and they were daily subjected to motility analysis either directly or after cryopreservation procedure as described by Fauvel et al. (1998). Finally, the sperm of 5 males were individually stored for 3 days at $4^{\circ} \mathrm{C}$ in Leibovitz $\mathrm{L} 15$ and aliquots were daily frozen in order to evaluate the capacity of stored sperm to fertilize eggs after the freezing/thawing process. After trials showing no deleterious effects of the direct addition of $10 \%$ pure DMSO to diluted sperm just before straw filling (unpublished), this technique was applied for all sample preparation in order to avoid overdilution of sperm. In order to assess the fertilizing ability, the following protocle was established: Unfertilized eggs were stripped from 3 LHRHa induced females then pooled and dispatched into 2000 egg aliquots. Fertilizations using each male semen after the different times storage, were performed in duplicates as described by Fauvel et al (1999) using $410^{10}$ spermatozoa per egg. The fertilization rates were individually assessed through the observation of 300 eggs of each of the 40 resulting batches.

\section{Statistical analysis.}

198 The analyses were performed by means of statistical package Statistica version 1998.0 (Statsoft, Tulsa, OK, USA). For each experiment the sperm samples of 5 males were used as replicates. The effects of media, dilution and time of conservation on the initial motility of gametes were studied by general linear model Two Way ANOVA after angular transformation since motility is expressed as a percentage of motile cells. Significant differences were analyzed by Holm-Sydak test

204 The effect of sperm storage on motility parameters (percentage of motile cells and average path velocity) with time after activation (TAA), was studied by covariance analysis and slope homogeneity model with TAA as a covariable.

\section{Results.}


210 The osmolarity of Urine is variable but of the same order as that of seminal plasma.

211 On the contrary, urine $\mathrm{pH}$ is variable but lower than that of semen (Table 1)

212 The $\mathrm{pH}$ of testicular and stripped semen were not significantly different $(P=0.209)$

213 On the contrary, the $\mathrm{pH}$ of pure semen was significantly higher than that of $10 \%$

214 and $20 \%$ urine added semen $(P<0.001)$, there was no interaction between factors

215 (Table1).

216 There was a significant difference of initial motility (percentage of mobile

217 spermatozoa at $10 \mathrm{~s}$. after activation) among the different levels of contamination

218 by urine $(p<0.01)$. In contrast, there was no statistically significant difference

219 among the different incubation times after allowing for the effects of differences in

220 contamination $(P=0,968)$.

221 The initial motility of $20 \%$ urine added sperm was significantly lower than those

222 recorded for sperm contaminated by either 0 or $10 \%$ urine $(P=0,021)$, while there

223 was no significant differences due to the duration of contamination The mean

224 percentages of motile sperm at activation are reported in table 2.

Modifications of sperm initial motility in relation to time of storage in different

227 media.

228 The initial motility (percentage of motile cells at $10 \mathrm{~s}$ after activation) of sperm kept

229 for 2 hours in the different conditions ranged from 65 to $85 \%$. The comparison of 230 mean initial motility by two way ANOVA with dilution conditions and time of 231 conservation as factors, revealed significant effects of both factors $(P<0.01)$. A

232 significant interaction between storage duration and medium composition was

233 noted $(P<0.01)$. Undiluted sperm showed a significant drop of motility at activation

2346 hours after collection while a similar drop down was observed respectively at $46 \mathrm{~h}$

235 and 71h post collection for sperm diluted in NAM and in Leibovitz L15 (Fig 1).

236

237 Effect of $\mathrm{pH}$ and $\mathrm{KHCO}_{3}$ in modified $\mathrm{L15}$ on initial sperm motility along

238 storage. 
The two way ANOVA with $\mathrm{pH}$ and $\mathrm{KHCO}_{3}$ as factors showed significant differences in motility due to both factors $(P<0.001)$ and there was a significant interaction between the factors $(\mathrm{P}<0.001)$. The media L7K and L8K (with potassium bicarbonate) induced a significantly lower initial motility than L7 and L8 .

There were no significant differences in the initial motility of sperm subjected to media L7, L8 and LK7, after 1, 6 and 21 hours of conservation. Then, there was a significant decrease of initial motility in all the media. In medium LK8, a significant decrease was recorded at $21 \mathrm{~h}$ of conservation (Fig 2 ).

Effect of dilution rate in modified L15 and time of storage on gamete initial motility.

The initial motility of sperm depends on both dilution and time of storage without interaction. The motility of sperm stored at dilution 1:5 is significantly higher $(P<0.05)$ than that of sperm diluted to $1: 2$ while the dilution 1:3 did not differ from the other dilutions. Moreover the motility at every time of conservation is significantly different $(P<0.01)$ from that of the previous time. (Fig 3$)$.

\section{Effect of chilled storage and further cryopreservation on the motility}

The slopes of motility decrease based on the percentage of motile spermatozoa were not significantly different between fresh and frozen sperm $(P>0.05)$ while they slightly but significantly differ with storage duration $(P<0.01)$. There was no interaction between conservation duration and cryotreatment $(p>0.05)$. Sperm showed a significantly higher slope of motility decay after 2 hours of conservation than after 22 and $46 \mathrm{~h}$, due to higher initial motility. Whatever the time of conservation, the slopes of motility decay of fresh and frozen spermatozoa were not different.

The slopes of sperm VAP (average path velocity) versus time after activation were not significantly different between fresh and frozen-thawed sperm $(P>0.05)$, but they vary with storage duration $(P<0.01)$. A significant interaction between freezing and time of storage before freezing $(P<0.01)$. The SNK test indicates that slopes 
of VAP of frozen-thawed sperms were not modified with time of conservation except that of fresh sperm after $46 \mathrm{~h}$ conservation which was significantly lower

271 (Fig 4).

272 Fertilization capacity of chilled stored sperm

273 There was no significant difference of fertilization rate between sperm subject to 274 different times of storage and then cryopreserved $(P=0.205)$.

\section{Discussion}

277 The management of artificial reproduction of captive fish requires a perfect coordination between sperm and egg collection unless a safe method of gamete conservation is setup. The development of large factorial crosses as well as the need of cryopreservation of sperm designed for large numbers of fish requires one to control the decay of sperm quality after collection. Among fish species, the ability of sperm to survive chilled is very variable from 34 days in rainbow trout (Stoss \& Holtz 1983) to some hours like in seabass the sperm of seabass of which presents a fast decay of motility potential after collection as reported by Sansone et al. (2001), and Peñaranda et al. (2008). In this species, the presence of urine in ejaculate does not seem to be the cause of this rapid loss of quality since, mixed to sperm at a concentration of $10 \%$, it did not modify sperm ability to start swimming even after 20 minutes of storage, while a $20 \%$ contamination instantaneously induces a drop of the motility. Moreover, as urine contamination modifies the acidity of the seminal fluid, a simple control of sperm $\mathrm{pH}$ allowed discarding potentially polluted sperm. The limited survival of seabass sperm is a bottleneck for the management of artificial fertilization and particularly, for the large factorial crosses to be performed in genetic studies where sperm must be collected from large numbers of males.

295 The dilution of sperm is compulsory for storage in tench (Rodina et al., 2004) or it increased the efficient duration of sperm storage in various species such as

297 sturgeon, turbot, striped bass, cod, haddock and smelt (Bobe \& Labbé 2008). The current work confirms seabass sperm to survive less than 6 hours if kept undiluted 
at $4^{\circ} \mathrm{C}$, while the use of adapted saline diluents increased the resistance of sperm to conservation by one day, making possible delayed fertilization.

301 The use of a more complex dilution medium than a simple saline medium such as the cell culture medium Leibovitz L15, actually improved the duration of conserved sperm survival by one more day with a slight but significant effect of the dilution rate on motility, 1:3 (sperm volume :medium volume) being better than 1:2. However the adequate dilution remained very low and quite similar to those suggested for different species (Bobe \& Labbé 2008) but less than those previously reported for seabass (1:6 in Sansone et al., 2001 and 1:20 in Peñaranda et al., 2008).

As was observed in turbot (Dreanno et al., 1998) and other fish species (Bobe \& Labbé, 2010), a contamination by urine affects sperm fertilization ability. In the present case, urine contamination by $20 \%$ immediately acidified the mix and decreased the initial motility observed at activation of sperm by seawater. However

313 this acidification of sperm microenvironment before activation may not be involved in sperm movement collapse since a similar decrease of $\mathrm{pH}$ due to dilution in $\mathrm{L} 15$

315 allowed a high motility and, in the range 7.34 to 8.10 , the $\mathrm{pH}$ of this conservation medium did not alter sperm motility at activation. This must be disconnected from

317 the sensitivity of seabass sperm to activating medium $\mathrm{pH}$ described by Billard 318 (1984). The addition of potassium to L15 that might help limiting sperm movement 319 as reported in salmonids (Morisawa \& Suzuki, 1980), hence improving conservation like in sterlet (Tsvetkova,1996), lowered the conservation capacity of

321 L15 medium in seabass. Moreover, the presence of bicarbonate which helps maturating sperm in salmonids (Morisawa and Morisawa 1988) as well as high $\mathrm{pH}$ decreased the survival capacity of sperm in L15. The covariance analysis of motility parameters reveals a gentle but significant decay of the number of motile spermatozoa in $\mathrm{L} 15$ during the storage at $4^{\circ} \mathrm{C}$, however, conservation in $\mathrm{L} 15$ did not significantly influence the impact of cryopreservation on the percentage of motile spermatozoa since there was no interaction. The significant effect of conservation on sperm velocity after cryopreservation may be an artifact since only 
fresh sperm at $46 \mathrm{~h}$ of conservation showed a slower initial velocity which seems abnormal.

331 Since fertilization trials using only $2.10^{5}$ spermatozoa per egg as advised in Fauvel et al. (1999) for secured production purposes, revealed a decay of fertilization rate

333 (unpublished) during the storage, we tested a higher (double) availability of sperm

334 in the current experiment. In that case, as an integrative result, L15 diluted sperm 335 maintained for 1 or 2 days in the fridge and further cryopreserved provided similar 336 fertilization rates as sperm frozen at collection time fertilization ratio, showing that 337 although existing, the decay of chilled stored sperm fertilizing ability can be overcome by an increase of sperm to egg ratio. This protocol may be acceptable for genetic purposes or production since such a ratio represents $1 \mathrm{ml}$ of sperm (or $4 \mathrm{ml}$ after dilution) to fertilize $10^{5}$ ova with a 75 to $90 \%$ success.

341 As a conclusion, on a practical point of view, this improvement of chilled storage capacity by the use of more complete diluents such as the cell culture medium Leibovitz L15, increases the duration of efficient conservation of seabass sperm compared to saline media in seabass, it improves the management of broodstocks for sophisticated crossbreedings in genetic purposes and it also opens the possibility to geographically disconnect freezing facilities from sperm collection sites then allowing the development of communal standardized cryobanks.

The use of L15 to keep chilled sperm alive for $24 \mathrm{~h}$ was already successfully applied in two of the main hatcheries in France for genetic management purposes.

351 Further investigation is, notwithstanding, required to explain the physiological mechanisms by which sperm survival is improved.

\section{Acknowledgment}

This study was performed within the project Cryoaqua supported by the French organization GIS/IBISA (Infrastructures Blologie Santé Agronomie).

\section{References}


Alavi, S.M.H.; Cosson, J. 2006: Sperm motility in fishes. (II) Effects of ions and osmolality: A review. Cell Biology International 30 1-14

Asturiano, J. F.; Pérez, L.; Garzón, D. L.; Marco-Jiménez, F.; Peñaranda, D. S.; Vicente, J. S.; Jover, M., 2004: Physico-chemical characteristics of seminal and development of media and methods for the cryopreservation of European eel sperm. Fish Physiol. Biochem. 30, 283-293.

Billard R., 1984 : Conservation des gamètes et insémination artificielle chez le bar et la daurade. L'aquaculture du bar et des sparidés, 95-116. Billard,R. and Barnabé G. eds, INRA publ., Paris.

Billard R., Cosson M. P., 1992: Some problems related to the assessment of sperm motility in freshwater fish. J.Exp. Zool. 261, 122-131

Bobe,J.; Labbe, C., 2010: Egg and sperm quality in fish. Gen. Comp. Endocrinol. $165,535-548$.

Bobe, J.; Labbé, C., 2009: Chilled storage of sperm and eggs. Methods in reproductive aquaculture, marine and freshwater species. 219-235. Cabrita, E.; Robles, V.; Herraez, P. eds. CRC Press Taylor \& Francis Group, Boca Raton, USA, ISBN 978-0-8493-8053-2..

Boryshpolets, S.; Dzyuba, B.; Stejskal, V.; Linhart, O., 2009: Dynamics of ATP and movement in Eurasian perch (Perca fluviatilis L.) sperm in conditions of decreasing osmolality. Theriogenol., 72, 851-859.

Cabrita, E.; Robles, V.; Herraez, P., 2009: Sperm quality assessment. Methods in reproductive aquaculture, Marine and freshwater species. Cabrita, E.; Robles, V.; Herraez, P. eds. CRC Press Taylor \& Francis Group, Boca Raton, USA, ISBN 978-0-8493-8053-2. 
Cherr, GN.; Morisawa, M.; Vines, C.A.; Yoshida, K.; Smith, E.H.; Matsubara, T.; Pillai, M.C. ; Griffin, F.J.; Yanagimachi, R., 2008: Two egg-derived molecules in sperm motility initiation and fertilization in the Pacific herring (Clupea pallasi). Int. J. Dev. Biol. 52, 743-52.

Christen, R.; Gatti, J. L.; Billard, R., 1987: Trout sperm motility- the transient movement of trout sperm is related to changes in the concentration of ATP following the activation of the flagellar movement. European J. Biochem. $166,3,667-671$.

400

Dreanno C. ; Suquet, M.; Desbruyères, E. ; Cosson, J. ; Le Delliou, H. ; Billard, R., 1998: Effect of urine on semen quality in turbot (Psetta maxima) Aquaculture, 169, 247-262

404

Dreanno, C.; Cosson, J.; Suquet, M.;Seguin, F.; Dorange, F.; Billard, R., 1999: Nucleotide content, oxydative phosphorylation, morphology, and fertilizing capacity of turbot (Psetta maxima) spermatozoa during the motility period. Mol. Reprod. Dev. 53, 2, 230-243.

409

411 Dupont-Nivet, M.; Karahan-Nomm, B.; Vergnet, A.; Merdy, O.; Haffray, P.; Chavanne, H.; Chatain, B.; Vandeputte, M., 2010: Genotype by environment interactions for growth in European seabass (Dicentrarchus labrax) are large when growth rate rather than weight is considered. Aquaculture 306, 365-368 
Fauvel C.; Omnès M.H.; Suquet M.; Normant Y., 1993 : Reliable assessment of overripening in turbot (Scophthalmus maximus) by a simple $\mathrm{pH}$ measurement Aquaculture, 117, 107-113

Fauvel C.; Suquet M.; Dreanno C.; Zonno V.; Menu B., 1998: Cryopreservation of sea bass (Dicentrarchus labrax) spermatozoa in experimental and production simulating conditions. Aquat. Living Resour., 11, 387-394

Fauvel C.; Savoye, O.; Dreanno C.; Billard R.; Cosson J.; Suquet M., 1999: Characteristics of captive seabass (Dicentrarchus labrax) sperm in relation to its fertilisation potential. J. Fish Biol. 54, 356-369.

Forniés, M. A.; Mañanós, E.; Carrillo, M.; Rocha, A.; Laureau, S.; Mylonas, C. C.; Zohar, Y.; Zanuy, S., 2001: Spawning induction of individual European sea bass females (Dicentrarchus labrax) using different GnRHa-delivery system. Aquaculture 202, 221-234.

Gwo, J.C., 2010: Fine structure, motility, and cryopreservation of spotted sea bass Lateolabrax maculatus (Moronidae, Teleostei) spermatozoa. J. Appl. Ichthyol. 26, 732-736.

Inaba, K., 2008: Molecular mechanisms of the activation of flagellar motility in sperm. Fish Spermatology, 267-280. Alavi S. M. H.; Cosson, J.J.; Coward, K.; Rafiee, ,G. eds. Alpha Science international Ltd, Oxford, ISBN 978-184265-369-2.

Kime, D. E.; Van Look, K. J.; McAllister, B. G.; Huyskens, G.; Rurangwa, E.;;Ollevier, F., 2001: Computer-assisted sperm analysis (CASA) as a tool 
for monitoring sperm quality in fish. Comp. Biochem. Physiol. 130, 425433.

Morisawa, S.; Morisawa, M.,1988: Induction of potential for sperm motility by bicarbonate and $\mathrm{pH}$ in rainbow trout and chum salmon. J. exp. Biol. 136, 13-22.

Morisawa, M.; Susuki, K., 1980: Osmolality and potassium ion; their role in initiation of sperm motility in teleosts. Science, $\mathbf{2 1 0}, 1145-1146$

Morisawa, M.; Susuki, K.; Morisawa,S., 1983: Effect of potassium and osmolarity

Peñaranda D. S.; Pérez, L.; Fakriadis, G.; Mylonas, C. C.; Asturiano, J. F., on spermatozoa motility of salmonid fishes. J. Exp. Biol. 107,105.

461 2008: Effects of extenders and cryoprotectant combinations on motility and morphometry of sea bass (Dicentrarchus labrax) spermatozoa. J. Appl. Ichthyol. 24, 450-455.

Rodina, M.; Cosson, J.; Gela, D.; Linhart, O., 2004: Kurokura solution as immobilizing médium for spermatozoa of Tench (Tinca tincaL.). Aquac. Int. 12, 119-131.

Rurangwa, E.; Kime, D. E.; Ollevier, F.; Nash, J. P., 2004: The measurement of sperm motility and factors affecting sperm quality in cultured fish. Aquaculture, 234, 1-4, 1-28.

A. L.; Occidente, M.; Matassino, D., 2002: Effects of extender composition; cooling rate; and 
freezing on the motility of sea bass (Dicentrarchus labrax) spermatozoa after thawing. Cryobiology 44, 229-239.

Stoss J.; Holtz W. 1983: Successful storage of chilled rainbow trout spermatozoa for up to 34 days. Aquaculture 31, 269-274.

Suquet. M.; Dorange, G.; Omnes, M.H.; Normant. Y.; Le Roux, A. ; Fauvel, C., 1993: Composition of the seminal fluid and ultrastructure of the spermatozoon of turbot (Scophthamus maximus). J. Fish Biol. 42, 509516.

Tanaka, S.; Zhang, H.; Yamada, Y.; Okamura, A.; Horie, N.; Utoh, T.; Mikawa, N.; Oka, H. P.; Kurokura, H., 2002: Inhibitory effect of sodium bicarbonate on the motility of sperm of Japanese eel. J. Fish Biol. 60, 1134-1141.

Toth, G. P; Ciereszko,A.; Christ S. A.; Dabrowski, K., 1997 Objective analysis of sperm motility in the lake sturgeon, Acipenser fulvescens: activation and inhibition conditions. Aquaculture. 154, (3-4), 337-348

Tsvetkova L.I.; Cosson J.; Linhart O.; Billard R., 1996: Motility and fertilizing capacity of fresh and frozen-thawed spermatozoa in sturgeons Acipenser baeri and A. ruthenus. Journal of Appl.Ichthyol, 12, 107-112.

Villani, P.; Catena, C., 1991 : Crioconserviazione di gamete maschili di spigola (Dicentrarchus labrax L .): Soluzione e metodologie. Riv.ital.Aquacol. 26, $217-226$ 
503 Wilson-Leedy J.G.; Ingermann R. L., 2007: Development of a novel CASA system 504 based on open source software for characterization of zebrafish sperm motility parameters. Theriogenology $67,3,661-672$.

506 Wilson-Leedy, JG; Kanuga, MK; Ingermann, RL., 2009: Influence of osmolality and ions on the activation and characteristics of zebrafish sperm motility. Theriogenol., 71, 7, 1054-1062.

509

510 


\section{Captions}

Table 1: Characteristics of urine and effects of the addition of urine to sperm on the $\mathrm{pH}$ and osmolarity of spermatozoa environment either collected from testes or by stripping ( $n=5$ males in both cases). Data are expressed as mean (SEM). The values associated to different letters are significantly different. The measures of osmolarities after 10 and $20 \%$ contamination were not replicated.

Table 2: Effect of urine contamination level (\% $\mathrm{v} / \mathrm{v}$ of urine added to sperm) and duration of contamination on initial motility of sperm (\% of mobile spermatozoa at 10 s. after activation). The values associated to different letters are significantly different

Figure 1: Variations of sperm initial motility (mean \pm SEM based on 5 males) in relation to time of conservation at $4^{\circ} \mathrm{C}$ from 2 to 71 hours in different conditions, respectively undiluted (Control), diluted in Leibovitz medium (L15) and diluted in Non Activating Medium or NAM (Fauvel et al. 1999). The different letters refer to significantly different values

Figure 2: Variations with time at $4^{\circ} \mathrm{C}$ of initial motility (\% mobile spermatozoa at $10 \mathrm{~s}$ assessed by CASA) after activation of chilled sperm subjected to different conservation conditions of $\mathrm{pH}$ and potassium ion concentration. Data are expressed as mean \pm SEM based on 5 males. The significant differences are illustrated by different letters

Figure 3: Effect of dilution rate on sperm survival during conservation illustrated by the initial motility. Data are expressed as mean \pm SEM based on 5 males. The significant differences are illustrated by different letters

Figure 4: Effect of storage duration (S) of chilled sperm on two main parameters of motility without and after cryopreservation based on 5 males. A: percentage of mobile spermatozoa (spz); B: Average Path Velocity of spermatozoa. Sperm motility was triggered by dilution of sperm into seawater and it was assessed at $10 \mathrm{~s}$ intervals of time after activation (TAA) until any movement ceased. Data are expressed as mean \pm SEM. 
Table 1

\begin{tabular}{|c|c|c|c|c|c|}
\hline & & Urine & No urine & $10 \%$ urine & $20 \%$ urine \\
\hline \multirow[t]{2}{*}{ Urine } & $\mathrm{pH}$ & $5.63(0.39)$ & & & \\
\hline & Osm & $348(62)$ & & & \\
\hline \multirow[t]{2}{*}{ Stripped sperm } & $\mathrm{pH}$ & & $8.06(0.03)^{a}$ & $7,30(0.10)^{b}$ & $7.31(0.2)^{b}$ \\
\hline & Osm & & $371(9)$ & 349 & 349 \\
\hline \multirow[t]{2}{*}{ Testicular sperm } & $\mathrm{pH}$ & & $7.91(0.02)^{a}$ & $7,19(0.06)$ & - \\
\hline & Osm & & - & - & - \\
\hline
\end{tabular}


Table2

\begin{tabular}{llll}
\hline & \multicolumn{2}{c}{ Mean (SEM) initial motility : \% mobile spermatozoa } \\
\hline Activation time & Immediate & After 10 min & After 20min \\
\hline $0 \%$ urine & ${ }^{\mathrm{a}} 53.3(8.8) \%$ & ${ }^{\mathrm{a}} 46.6(14.5) \%$ & ${ }^{\mathrm{a}} 43.3(12.1) \%$ \\
$10 \%$ urine & ${ }^{\mathrm{a}} 43.3(14.5) \%$ & ${ }^{\mathrm{a}} 43.3(8.8) \%$ & ${ }^{\mathrm{a}} 53.3(3.3) \%$ \\
$20 \%$ urine & $\mathrm{b} 6.6(3.3) \%$ & $\mathrm{~b}_{15.0}(7.6) \%$ & $\mathrm{~b}_{10.0}(5.8) \%$ \\
\hline
\end{tabular}


Figure 1

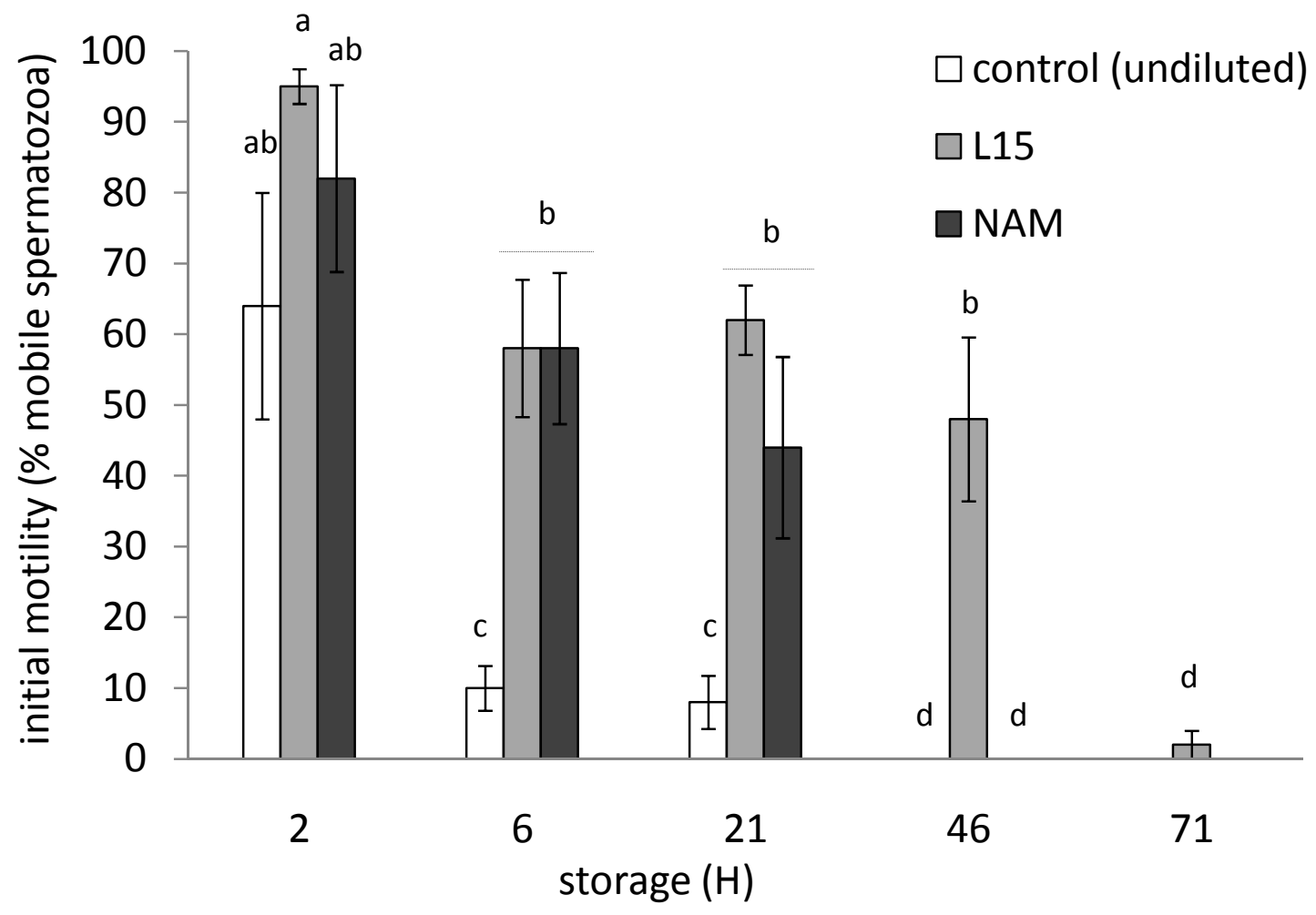


Figure 2

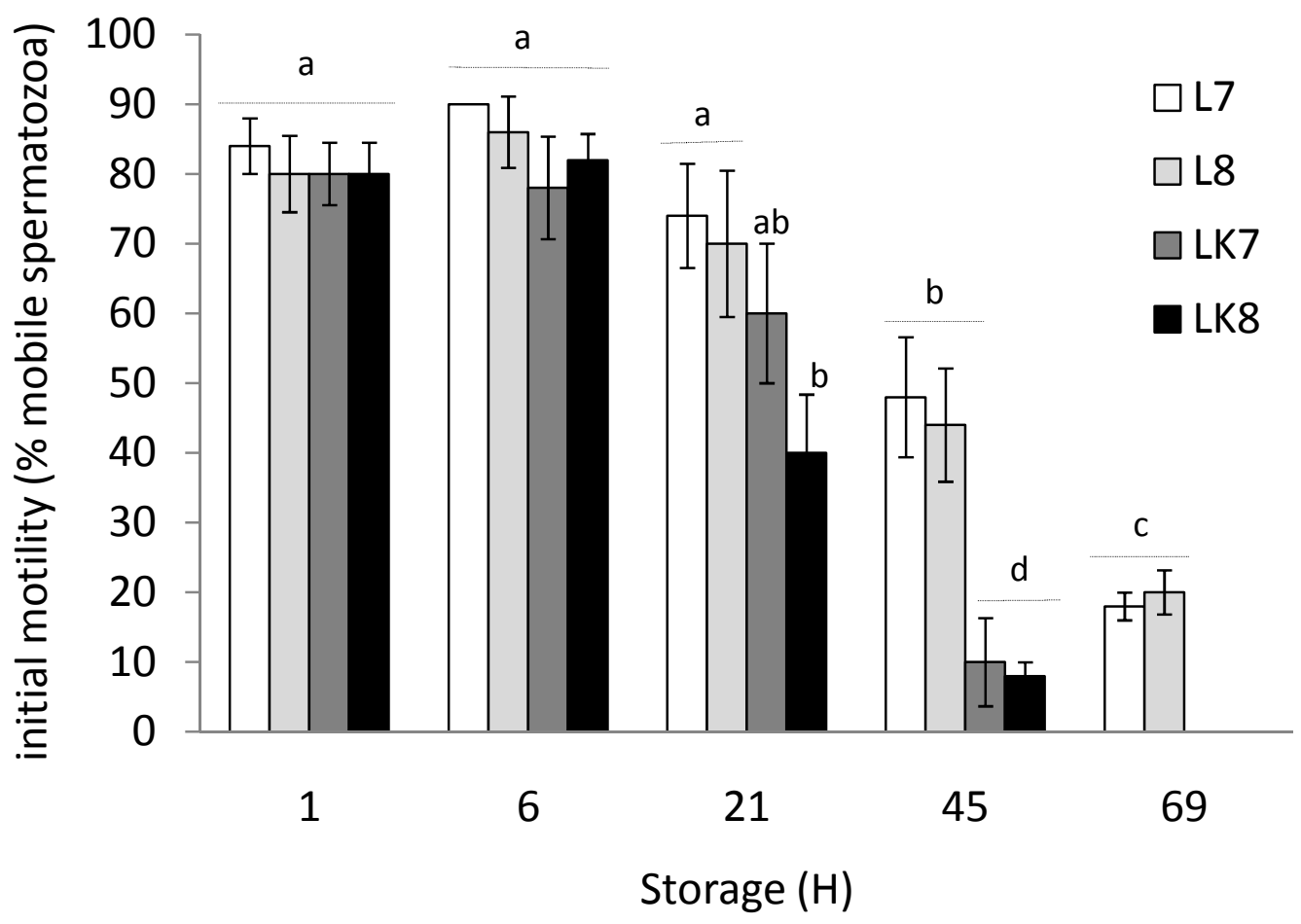


Figure 3

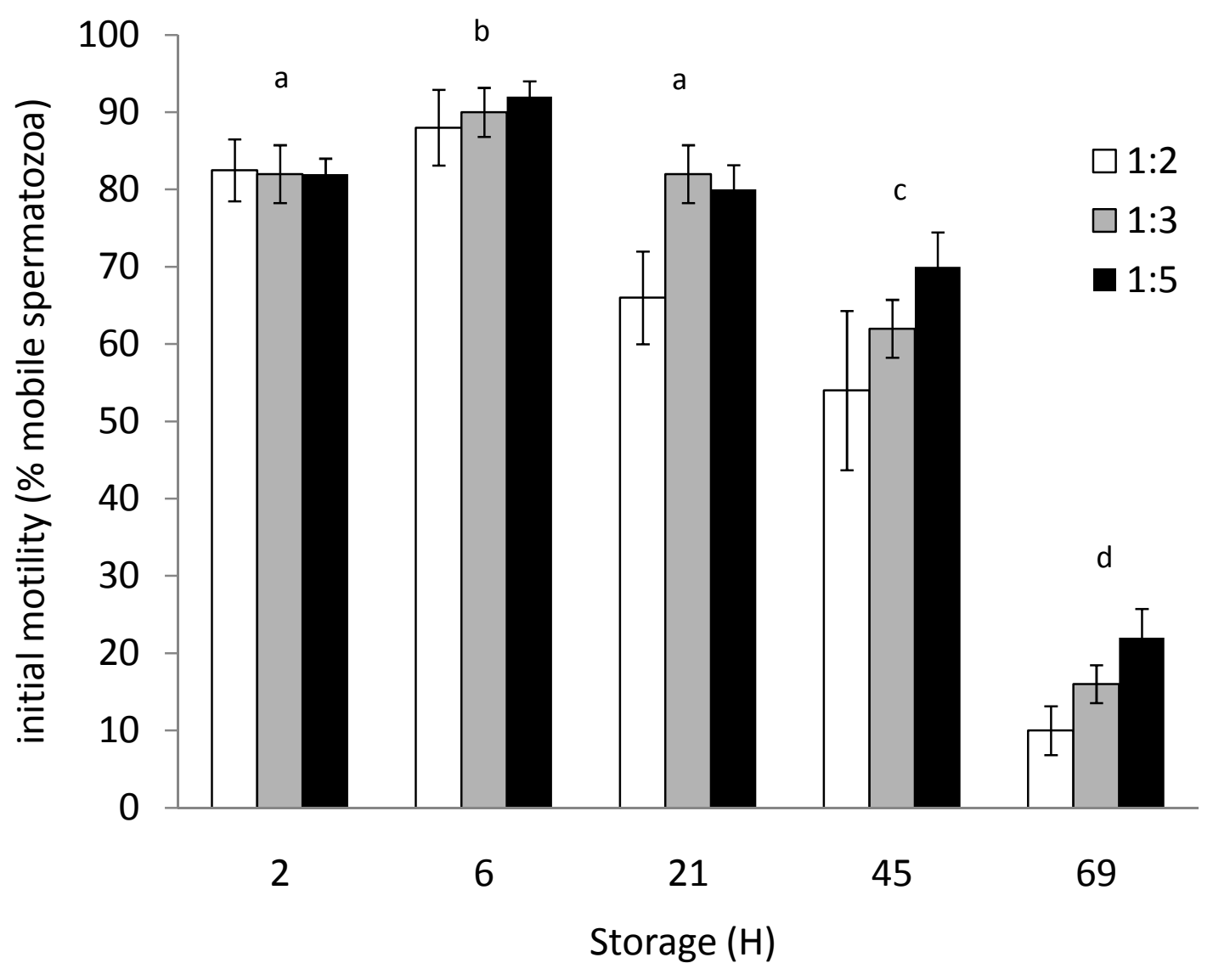


Figure 4

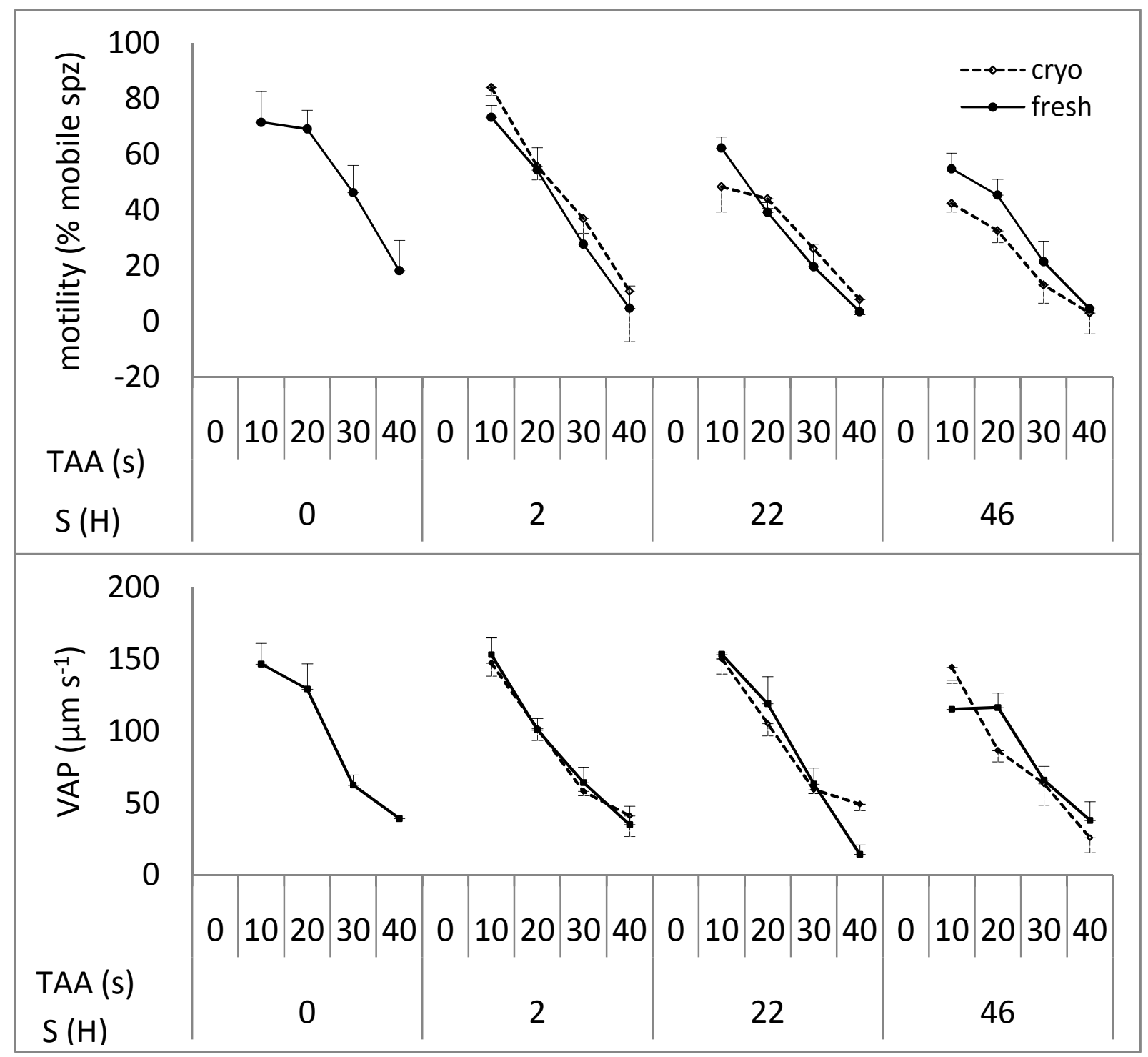

